\title{
Limitations of Extending Juvenile Psychopathy Research Assessment Tools and Methods to Forensic Settings
}

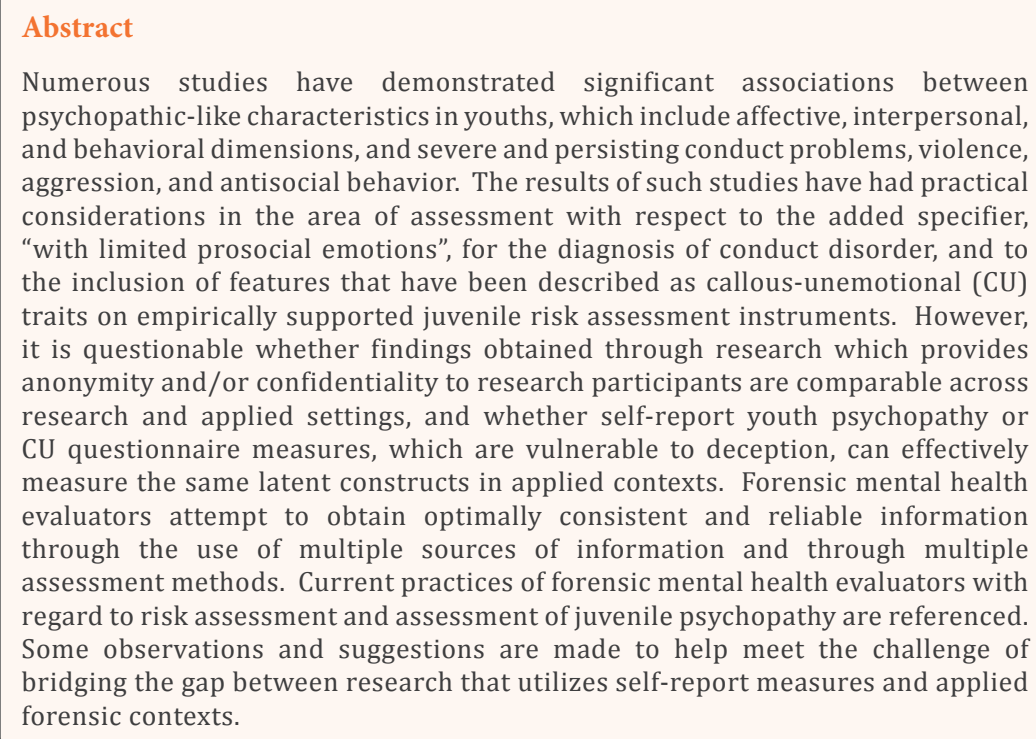

Numerous studies have demonstrated significant associations between psychopathic-like characteristics in youths, which include affective, interpersonal, and behavioral dimensions, and severe and persisting conduct problems, violence, aggression, and antisocial behavior. The results of such studies have had practical considerations in the area of assessment with respect to the added specifier, "with limited prosocial emotions", for the diagnosis of conduct disorder, and to the inclusion of features that have been described as callous-unemotional (CU) traits on empirically supported juvenile risk assessment instruments. However, it is questionable whether findings obtained through research which provides anonymity and/or confidentiality to research participants are comparable across research and applied settings, and whether self-report youth psychopathy or CU questionnaire measures, which are vulnerable to deception, can effectively measure the same latent constructs in applied contexts. Forensic mental health evaluators attempt to obtain optimally consistent and reliable information through the use of multiple sources of information and through multiple assessment methods. Current practices of forensic mental health evaluators with regard to risk assessment and assessment of juvenile psychopathy are referenced. Some observations and suggestions are made to help meet the challenge of bridging the gap between research that utilizes self-report measures and applied forensic contexts.

Opinion

Volume 4 Issue 1 - 2015

Robert Semel*

Principal Investigator, USA

*Corresponding author: Robert Semel, Principal investigator, 1242 E. 70th Street Brooklyn New York, 11234, USA, Email: robertsemelpsyd@gmail.com

Received: October 15, 2015 | Published: October 16, 2015

\section{Opinion}

Psychopathic or psychopathic-like characteristics in youths have been studied extensively over the past two decades across community, clinic-referred and adjudicated samples [1-4]. Frick and White [2] asserted that a review of the literature provides "compelling evidence" of an association between psychopathic traits and severe conduct problems, violence, aggression, and delinquency across samples of youths. In more recentyears specific dimensions of psychopathy, especially callous-unemotional (CU) traits, which reflect affective features of psychopathy, have become the focus of numerous studies [5]. An accumulation of empirical evidence strongly suggests that youths with high levels of CU traits represent a subgroup of antisocial youth who display more severe and persistent aggression and violence, especially including both instrumental and reactive aggression, and a general lack of empathy and guilt [1-4,6-7]. A recent comprehensive review of the literature by Frick, et al. [4] on the role of CU traits in understanding severe conduct problems included 269 studies published after 1990, 191 of which were published in 2007 or later. The review concluded that the research seems to indicate that "... children and adolescents with severe conduct problems and elevated CU traits show distinct genetic, cognitive, emotional, biological, environmental, and personality characteristics that seem to implicate different etiological factors underlying their behavior problems relative to other youths with severe conduct problems". Measures of CU traits have shown stability across childhood and adolescence at levels that are comparable to those reported for other problem areas studied in child and adolescent psychopathology [8]; and see Frick, et al. [3] for a review. Still, despite finding moderate stability of psychopathy from early adolescence into young adulthood, Lynam, et al. [8] also found that "most individuals identified as psychopaths at age 13 will not receive such a diagnosis at age 24". Additionally, decreases in CU traits for some youths, and decreases associated with family based interventions in particular, suggest that such traits are malleable and may be positively altered in association with certain features of the child's psychosocial environment [2,9].

\section{Relevance of Assessing Juvenile Psychopathy Like Traits in Clinical and Forensic Contexts}

The study of particular traits or dimensions of psychopathy in youths (including affective, interpersonal, and behavioral dimensions, as illustrated, for example, by callous lack of empathy, shallow emotions, egocentricity, lying/deceitfulness, manipulation/exploitation of others, narcissism, impulsivity, and anti-social behavior) has already led to practical considerations in the realms of clinical diagnostic assessment, assessment of risk for delinquent recidivism, and assessment of psychopathic characteristics in adolescents. The diagnostic criteria for Conduct Disorder in the American Psychiatric Association (2013) Diagnostic and Statistical Manual of Mental Disorders (5th edn, DSM-5) [10] include the specifier "with limited prosocial emotions", indicating a pattern of interpersonal and emotional functioning characterized by a lack of remorse or guilt, deficient or shallow affect, callous lack of empathy, and a lack of concern about performance at school, work, or other important activities (two or more of the four traits must be present over a period of 12 months and observed in more than one relationship or setting, requiring multiple sources of information about the youth). Also, impaired capacity for, or inadequate development of remorse, 
guilt, empathy, and concern for others are included among risk factors or items in the most commonly used and validated risk assessment instruments for youths who already have juvenile justice involvement. These empirically supported measures for assessing violence risk and/or recidivism in adolescents are most often used in the context of sentencing or disposition decisions and for planning of therapeutic interventions $[11,12]$ These specialized risk assessment tools such as the Youth Level of Service/Case Management Inventory (YLS/CMI) [13], the Structured Assessment of Violence Risk in Youth [SAVRY] [14], and the Risk-Sophistication-Treatment Inventory [RSTI] [15], require the evaluator to obtain pertinent information from multiple sources in order to integrate data in an empirically supported assessment of risk for violent and/or non-violent recidivism. Typically, such instruments are used to estimate overall low, moderate, or high levels of risk, to identify specific contextual or dynamic risk factors that increase risk of recidivism and are in need of being targeted for treatment, and to identify protective factors that may help mitigate risk. The Psychopathy Checklist: Youth Version [PCL:YV] [16], is designed for use in research, clinical, and forensic settings as a dimensional measure to evaluate the presence and severity of psychopathic traits in adolescents, but it has also demonstrated predictive validity in assessing risk of general, violent, and nonviolent recidivism in youth offenders at levels of accuracy comparable to the YLS/ CMI and the SAVRY [17]. The PCL:YV authors [16] advise specific limitations on its use for diagnostic and legal purposes. The assessment process in using the above risk assessment measures as well as the PCL:YV typically includes comprehensive semistructured interview(s) of the youth, information about the youth obtained from parent/guardian, and from teachers, if available, and review of legal record and other relevant records that may be available such as mental health and educational records.

As suggested above, mental health professionals who conduct assessments of youths in clinical and forensic contexts typically obtain multiple sources of information about the youth Indeed, multiple sources of information should be obtained for each area assessed in forensic contexts, with adults and with juveniles $[18,19]$. Thus, if considering the presence of CU traits diagnostically if a youth meets criteria for Conduct Disorder, or as part of a risk assessment procedure, an evaluator most probably will not rely on self-report of the youth obtained through interview and perhaps use of questionnaires as the sole methods of assessment. Furthermore, even with respect to the study of CU traits, it has been asserted unequivocally that there is a need for assessments that include multiple informants in order to guide clinical practice $[3,4,20]$. However, some of the tools and methods employed in research that have led to great advances in the identification of psychopathic-like traits in youths and to cognitive, emotional, biological, and environmental correlates of these traits, identification of possible etiological factors, and also the study of treatment approaches, may have limited application in clinical and forensic settings. This will be the focus of the remainder of this paper, with particular association to juvenile forensic assessments ordered by courts to assist with legal disposition. Such assessments typically aim to identify mental health problems and treatment needs and the most appropriate settings for the juvenile (e.g., home vs. restricted setting) in order to minimize the risk of harm to others. Whereas forensic mental assessments may be ordered by courts to address other specific legal issues (e.g., competence to stand trial, capacity to waive Miranda rights, waiver of jurisdiction from juvenile to criminal court), evaluations in juvenile courts are most often ordered in the legal context of post adjudication disposition [21-23]

\section{Limitations of Extending Juvenile Psychopathy Research Methodology and Findings to Clinical and Forensic Settings}

The voluminous body of research that has been accumulating in the study of psychopathic and CU traits in youths has depended primarily on methodology that provides research participants, including those in juvenile justice settings, with anonymity and/or confidentiality. Such conditions may facilitate optimal cooperation and openness on the part of study participants who are assured that their responses will have no external consequences. Also, this research has been advanced to a notable degree through the utilization of structured, questionnaire format self-report and/or other informant (usually parent) report measures of these traits, in conjunction with, or as an alternative to use of the PCL:YV. The PCL:YV requires extensive training of raters and takes approximately two hours to complete [16]. Whereas some researchers regard the PCL:YV as the most reliable and valid measure of psychopathic traits, particularly for incarcerated adolescents [24], it also has been asserted that there is no "gold standard" measure of juvenile psychopathy [2526], and no gold standard measure of CU traits in particular [27]. Skeem \& Cauffman [26] found both the Youth Psychopathic Traits Inventory (YPI) [28], a self-report measure, and the PCL:YV to be reliable measures that were significantly predictive of short-term antisocial behavior in incarcerated juvenile offenders, despite the finding of only moderate association between the two measures. Skeem \& Cauffman [26] suggested that the YPI may be considered as a complementary method to the PCL:YV for the understanding and assessment of the juvenile psychopathy construct, with one measure not necessarily being more valid than the other. Among other empirically supported measures of psychopathy dimensions or the affective/CU dimension specifically are the Antisocial Process Screening Device (APSD) [29], which, like the PCL:YV, is a downward extension of the Hare Psychopathy Checklist-Revised (PCL-R) [30], and the Inventory of CallousUnemotional Traits (ICU) [31], which was derived from the APSD and designed as a more comprehensive CU measure. Both of these measures have informant (i.e., parent, teacher) and self-report forms. Also, both the APSD and the ICU were used in developing criteria for the DSM-5 conduct disorder specifier "with limited prosocial emotions".

Psychometrically reliable and valid questionnaire measures offer certain advantages when compared to labor intensive measures that are dependent on lengthy interview and file review. Validated self-report measures may provide a distinct sampling of psychological constructs under standardized administration and scoring procedures, thus controlling for some sources of error variance. Typically, narrow-band psychological measures that assess limited variables also are brief in length and time saving, which is advantageous for studies involving large numbers of participants and multiple variables of interest. However, advantages gained by the use of brief, self-report measures may be compromised by response styles that affect the accuracy of self-report. In forensic settings, youths may attempt 
to present a positive impression (impression management) by denying, minimizing, or otherwise underreporting problematic, dysfunctional behavior, attitudes, and emotions [32-38]. At the same time, they may present a socially desirable response style in which they portray themselves as virtuous, problem-free, and well-adjusted. Denial of problematic behaviors, such as aggressive, antisocial, disruptive behaviors, is not unexpected in the evaluation of youths in a juvenile justice context where the evaluation might have bearing on legal decisions with potential for restriction of freedom [35,37,39-40]. Murrie \& Cornell [34], Penney \& Skilling [35], and Pinsoneault [41], among others, suggest that in forensic settings one may encounter a higher base rate of youths who exhibit psychopathic personality traits, such as dishonesty, superficiality, deceptive self-presentation, and who may produce greater response biases on self-report measures of psychopathology. Indeed, level of psychopathic traits and level of socially desirable response were found to moderate the degree of discrepancy between youth and parent reports in youths who were court-ordered to undergo mental health evaluations [35]. Kahn et al. [42] found that youths high on CU traits (primary psychopathy variant) as measured by the APSD had significantly poorer credibility ratings than those in the secondary cluster or the anxious-conduct cluster. They speculated that youths in the primary psychopathy group were more likely to underreport problems relative to the report of their parents. It has also been noted that self-report scales generally consist of items that are transparent in the endorsement of socially undesirable qualities which can further lead to underreporting or denial of problems [34]. Murrie \& Cornell [34] asserted that there is a need for more research on '...the veracity of youths' self-reports and their willingness to reveal undesirable information about themselves, in both research and clinical contexts".

With respect specifically to the assessment of psychopathic and CU traits, various investigators have questioned whether selfreport measures can be applied in clinical or forensic contexts. As noted by Vincent, Kimonis \& Clark [43], self-report measures of youth psychopathic traits are limited by their inability to detect deception, as well perhaps as limited self-awareness of youths. Boccaccini et al. [44], Colins, et al. [45], Dolan \& Rennie [46], Kruh et al. [47], Vahl et al. [48] opine that the use of self-report measures may yield different outcomes in applied as opposed to research contexts. The results obtained via study procedures that afford research participants anonymity and/or confidentiality of their test responses may be different than those obtained in situations in which test responses are not confidential and may be used to make legal or rehabilitative decisions about the youths. Even the YPI, which was methodically developed to minimize response bias due to social desirability and lack of insight by creating items that frame psychopathic features as abilities rather than deficits [28], may be vulnerable to response bias in contexts in which legal or therapeutic decisions may be made $[28,36,46]$. Indeed, Andershed et al. [28] stated that the YPI "...is a research tool (that)...is only intended to be used in research settings where anonymity is guaranteed and where the responses on the instrument have no consequences for the individual". They stated further that "...it is likely that a self-report of psychopathic traits would work in a less valid manner in institutionalized samples than among non-referred youths". Thus, the research base that has greatly advanced the understanding of youth psychopathy and CU traits may have limited application in forensic evaluations where information is not kept confidential from the court and where the tools and methods selected should have empirical support for their use with the appropriate population.

Additionally, while many studies have included only youth self-report psychopathy or CU measures, even studies that have included parent-report measures have not necessarily resulted in more accurate or valid measurement of psychopathy/CU traits. For example Fink et al. [49] found youth self-reports but not parent reports to be significantly correlated with the PCL:YV. The investigators viewed the latter finding as consistent with other literature [50] suggesting that parent report may be less reliable than self-report in the assessment of adolescent youth antisocial behavior and attitudes, which may be associated in part with lower levels of supervision and knowledge of the adolescent's activities. Thus, the research literature on juvenile psychopathy and CU traits does not support using parent report measures as optimal sources of information to the exclusion of youth selfreport measures.

\section{Current Practices of Forensic Mental Health Evaluators}

As noted earlier, when evaluators in clinical settings and in juvenile forensic settings assess psychopathic-like traits for diagnostic purposes or as part of risk assessment, with relevance to treatment needs, they typically employ multi-method, multiinformant assessment procedures. I turn now to address some specific current practices of forensic mental health evaluators in conducting evaluations for juvenile courts. It should be noted first that currently existing measures of juvenile psychopathy or CU traits are not psychological tests, per se, or diagnostic instruments that can yield valid cutoff scores for determining whether a particular youth has a psychopathic personality disorder or would continue to have such disorder into adulthood [43]. Among existing measures, the PCL:YV and the informant version of the APSD for children ages 6 to 13 (the two measures considered by Vincent et al. [43], as having sufficient evidence to warrant their use in forensic contexts) are consistent with many of the guidelines for use in forensic contexts as proposed by Heilbrun [51], i.e., they are commercially available with accompanying manuals that describe their development, psychometric properties, and administration procedures; they have demonstrated empirical support for reliability and validity; they are listed in and have been reviewed in Mental Measurements Yearbook [52-53]; they have been reviewed in peer-reviewed journals; and empirical support for their use continues to be studied. They do not incorporate measures of response style, per se, as recommended by Heilbrun [51], and by Heilbrun \& Locklair [18], although assessment of response style is considered. Item 1 of the PCL:YV, "Impression Management", involves the evaluator's assessment of the youth's interpersonal style as it may affect the reliability of the information being provided by the youth and also involves comparing such information with information obtained by third party sources. This is consistent with principles of forensic mental health assessment which include use of third-party information in assessing response style [18,19].

Heilbrun [51], Heilbrun and Locklair [18] , Heilbrun et al. [19] also proposed that forensic mental health assessments, including the use of psychological testing in forensic assessments, should be relevant to the legal issue under consideration or to a psychological construct underlying the legal issue. A survey 
of forensic mental health clinicians conducted by Viljoen, et al. [54] found that among survey respondents who conduct juvenile offender assessments, approximately $90 \%$ assess risk of violence or reoffending. The contexts or purposes of risk assessments were primarily for sentencing/disposition planning, but also were being used frequently in cases involving transfer of juveniles to or from criminal court. While interviews of the offender were used nearly all of the time in juvenile risk assessments, and interviews of caretaker were frequently used, risk assessment tools also were used frequently (most commonly used was the SAVRY). Psychopathy measures (i.e.,PCL:YV or PCL-R) were used always or almost always by one third of the clinicians and $78 \%$ of survey respondents reported use of psychopathy measures at least once in a while. However, less than $3 \%$ of these survey respondents indicated that their assessment reports state whether the juvenile offender "is or is not a psychopath". Less than one third indicated that their reports explicitly refer to the juvenile offender having psychopathy related characteristics. On the other hand, many of the survey respondents (44.5\%) indicated that they describe psychopathic characteristics without explicitly referring to such characteristics as psychopathic. As noted by Viljoen et al. [54], it would appear that most forensic mental health evaluators who conduct juvenile offender assessments have concerns about the appropriateness of the use of the term "psychopath" as applied to youth. The authors of the PCL:YV [16] decisively eschew use of the diagnostic label "psychopath" when describing youth evaluated with the PCL:YV. They recommend that the Total score be interpreted as a dimensional measure of psychopathic features. They also note that the term "psychopath" is a psychological, rather than a legal construct. In this vein, Vincent et al. [43] opine that "the research suggests that there is currently no evidence that juvenile psychopathy assessments can be used to discriminate youths who will continue to offend violently well into their adult years from youths who will desist in early adulthood". They suggest that "psychopathic traits in adolescence should be seen as a risk factor that will be dynamic for the majority of youths and, if present, marks the need for intensive treatment and a high likelihood for serious reoffending over a period of as long as 3 years". It would appear from the survey conducted by Viljoen et al. [54] that risk assessment and psychopathy measures with juvenile delinquents are being used primarily with the consideration of more short-term time frames for disposition planning.

\section{Conclusion and Future Directions for Study and Assessment of Psychopathy Traits in Youths}

Mental health evaluators who evaluate youths with conduct problems in clinical and forensic contexts may assess CU traits either for diagnostic purposes or as part of a risk assessment for violence or reoffending, both of which have relevance to treatment needs and planning. The most commonly used risk assessment instruments for juveniles include items such as callousness, lack of, or low levels of empathy, remorse, or guilt, albeit, such features account only for one or two items on these instruments. The SAVRY conceptualizes such features as dynamic, rather than static risk factors, and thus potentially amenable to change. Risk assessment tools such as the SAVRY are frequently utilized by forensic mental health evaluators in juvenile delinquency assessments (the YLS/CMI is often utilized by probation officers). Such instruments call upon the evaluator to make judgments in their ratings of what are, in essence, one or more CU items contained within such measures, using multiple sources of information. As per the survey conducted by Viljoen et al. [54], reports for court that include juvenile risk assessments almost always include the evaluator's rationale for risk judgment and they frequently include limitations of the evaluator's judgments. There are limitations in the accuracy of all risk assessment instruments [55]. To the extent that risk assessment instruments developed for youth have shown strong relationships with general offending and violent recidivism (i.e., the SAVRY, YLS/CMI, and the PCL:YV), none of these instruments have been shown to be perfect in their predictions [56]. In addition to these expert rating risk assessment measures, there is currently an accumulated and continuously developing empirical base of support for construct validity of a few self-report psychopathy or CU measures, albeit, the vast multitude of these studies have been conducted predominantly in research contexts. Forensic evaluators might consider whether or under what conditions judicious use of a self-report CU measure such as the self-report version of the APSD or ICU, both of which were used in developing criteria for the DSM-5 conduct disorder specifier "with limited prosocial emotions", might be appropriate as one component of a multi-method assessment; and, if so, how to make use of such a measure. As noted also by Viljoen et al. [54], it is not as yet evident how forensic evaluators should communicate information pertaining to psychopathy for juveniles as well as adults.

In looking toward potentially narrowing the gap between research that utilizes self-report measures under conditions of confidentiality and/or anonymity and the suitability of including self-report psychopathy measures in applied contexts, several considerations might be helpful. One is that some published studies (see, for example, $[48,57,58]$ ) were based on data that were obtained via standard mental health assessment protocols utilized for clinical purposes in juvenile detention and correctional facilities. In those studies the assessments were not confidential. Archived data were subsequently de-identified before use in research, consistent with relevant ethical guidelines. Such studies demonstrated that, similar to other studies that were conducted strictly for research, measures such as the APSD, ICU, and the YPI were significantly associated with external criteria such as violence and institutional misconduct. The results of such studies are promising. It should be noted, though, that the motivation to underreport might be different for youths who have already been sentenced and placed in a juvenile facility as compared to youths who have been adjudicated delinquent and are currently being evaluated for disposition purposes. A second consideration is that many forensic mental health evaluators include one or more standardized measures of personality and psychopathology, such as the MMPI-A [59] or the MACI [60] that incorporate response style measures. These "built-in" test validity indicators help identify the likely influence of an underreporting or over reporting response style on the accuracy of the test results. While test scores on the validity scales of the MMPI-A that suggest a youth was very defensive in responding to test items could not be directly extrapolated to a separate self-report measure such as the ICU, such test scores would provide some basis for judgment about the accuracy of information provided by the youth, especially if other sources of information also suggested that the youth was being defensive or deceptive. Ultimately, standardization of 
self-report psychopathy or CU measures with normative data for juvenile forensic groups and with empirical support for the validity of such measures would support their use in forensic assessments. At the present time, consideration might be given to use of the self-report APSD or ICU, or the YPI, as informal, nonscored measures to be used as part of the interview process. That is, after the youth completes such a measure the evaluator might select and query particular responses in order to expand or refine the assessment1. Additionally, the need for further research on measures to detect response bias in youth informants, in both research and applied contexts, has been noted [34]. Some studies (see for example [47,61-63]) have included stand-alone measures of social desirability (SD) such as the Marlowe-Crowne Social Desirability Scale [64], Edwards Social Desirability Scale [65], and the Children's Social Desirability Questionnaire [66]. Only the latter scale was developed for youth and its application and validity in forensic contexts has not received adequate study. Further study of this measure in research on juvenile psychopathy might be helpful. The development and validation of brief, standalone response style measures, and particularly a scale that can provide a valid measure of underreporting/social desirability in adolescents in forensic contexts, could also be quite helpful in making judgments about the accuracy of information provided by youths via interview and other self-report measures included in assessments2. Smith [37] identified the need for test developers to incorporate validity scales to detect response bias in the reports of youths, as well as those of parent and teacher reporters who also are vulnerable to bias (perhaps especially parents of adjudicated delinquents in forensic contexts). Not only is there is no single "gold standard" method or measure of psychopathology, including psychopathy traits, it has also been asserted that there is no "gold standard" approach for applying and interpreting multimethod assessments, though advances are being made toward improving clinical decision making [67]. How to best interpret and integrate discrepant information from different sources remains a challenge inresearch, clinical and forensic contexts, including the assessment of psychopathy and CU traits in juveniles.

\section{Notes}

1. The author developed an exploratory 25-item self-report questionnaire intended to assess CU traits which includes some items that might not suggest an undesirable mode of feeling about situations for some youths who may be higher on the dimension of callousness. Some items incorporate semantics that are blunt and bold. Several items reflect contemporary youth-oriented verbiage and use syntax consistent with how certain youths in American culture express themselves. This scale is available for research purposes upon request to the author.

2. The author developed an exploratory 32-item self-report scale intended as a stand-alone measure for the assessment of positive response bias in youths in contexts where the motivation for positive impression management may be particularly heightened, such as court-ordered evaluation of juvenile delinquents for disposition purposes. The scale is composed of items suggesting denial vs. admission of common human faults, weaknesses, and negative emotions, and assertion of unqualified virtues and good character. Six of the 32 items contain specific reference to a legal context, with mention of court, arrest, or probation. This scale is available for research purposes upon request to the author.

\section{Author Biography}

Robert A. Semel, Psy.D. works as a licensed psychologist for the New York State Office of Mental Health at South Beach Psychiatric Center where he conducts Family Court evaluations. I am the sole author of this manuscript. I have no potential conflicts of interest with respect to the research, authorship, and/or publication of this article. I received no financial support for the research and/ or authorship of this article.

\section{References}

1. Frick PJ, Dickens C (2006) Current perspectives on conduct disorder. Curr Psychiatry Rep 8(1): 59-72.

2. Frick PJ, White SF (2008) Research review: The importance of callousunemotional traits for developmental models of aggressive and antisocial behavior. J Child Psychol Psychiatry 49(4): 359-375.

3. Frick PJ, Ray JV, Thornton LC, Kahn RE (2014) Annual research review: A developmental psychopathology approach to understanding callous-unemotional traits in children and adolescents with serious conduct problems. J Child Psychol Psychiatry 55(6): 532-548.

4. Frick PJ, Ray JV, Thornton LC, Kahn RE (2014) Can callous-unemotional traits enhance the understanding, diagnosis, and treatment of serious conduct problems in children and adolescents? A comprehensive review. Psychol Bull 140(1): 1-57.

5. Horan JM, Brown JL, Jones SM, Aber JL (2015) Assessing invariance across sex and race/ethnicity in measures of youth psychopathic characteristics. Psychol Assess 27(2): 657-668.

6. Kimonis ER1 Frick PJ, Skeem JL, Marsee MA, Cruise K, et al. (2008) Assessing callous-unemotional traits in adolescent offenders: Validation of the Inventory of Callous-Unemotional Traits. Int J Law Psychiatry 31(3): 241-252.

7. Kimonis ER, Fanti K, Goldweber A, Marsee MA, Frick PJ, et al. (2014) Callous-unemotional traits in incarcerated adolescents. Psychol Assess 26(1): 227-237.

8. Lynam DR, Caspi A, Moffitt TE, Loeber R, Stouthamer-Loeber M (2007) Longitudinal evidence that psychopathy scores in early adolescence predict adult psychopathy. J Abnorm Psychol 116(1): 155-165.

9. Hawes DJ, Price MJ, Dadds MR (2014) Callous-unemotional traits and the treatment of conduct problems in childhood and adolescence: A comprehensive review. Clin Child Fam Psychol Rev 17(3): 248-267.

10. American Psychiatric Association (2013) Diagnostic and statistical manual of mental disorders (5th edn). American Psychiatric Publishing, Arlington, VA.

11. Hoge RD, Andrews DA (2010) Evaluation for risk of violence in juveniles. Oxford University Press, New York, USA, pp. 192.

12. Salekin RT (2015) Forensic evaluation and treatment of juveniles: Innovations and best practice. American Psychological Association, Washington, DC, USA.

13. Hoge RD, Andrews DA (2002) The Youth Level of Service/Case Management Inventory: User's manual. Multi-Health Systems, Toronto, Ontario, Canada.

14. Borum R, Bartel PA, Forth AE (2006) Structured Assessment of Violence Risk in Youth (SAVRY): Professional manual. In: Lutz FL (Ed.), 


\section{Psychological Assessment Resources.}

15. Salekin RT (2004) Risk-Sophistication-Treatment Inventory: Professional manual. In: Lutz FL (Ed.), Psychological Assessment Resources.

16. Forth AE, Kosson DS, Hare RD (2003) The Psychopathy Checklist: Youth Version manual. Multi-Health Systems, Toronto, Ontario, Canada.

17. Olver ME, Stockdale KC, Wormith JS (2009) Risk assessment with young offenders: A meta-analysis of three assessment measures. Criminal Justice and Behavior 36(4): 329-353.

18. Heilbrun K, Locklair B (2016) Forensic assessment of juveniles. In: Heilbrun K, DeMatteo D, Goldstein NES (Eds.), APA Handbook of psychology and juvenile justice. American Psychological Association, Washington DC, USA, pp. 345-363.

19. Heilbrun K, Marczyk GR, DeMatteo D, Zillmer EA, Harris J, et al. (2003) Principles of forensic mental health assessment: Implications for neuropsychological assessment in forensic contexts. Assessment 10(4): 329-343.

20. Lee Z, Salekin RT, Iselin AM (2009) Psychopathic traits in youth: Is there evidence for primary and secondary subtypes? J Abnorm Child Psychol 38(3): 381-393.

21. Archer RP (2005) MMPI-A: Assessing adolescent psychopathology. (3rd edn), Lawrence Erlbaum Associates, Mahwah, NJ, USA.

22. Grisso T (2013) Forensic evaluation of juveniles. (2nd ed.), Professional Resource Press, Sarasota, FL, USA.

23. Grisso T, Vincent G (2005) The context for mental health screening and assessment. In: GrissoT, Vincent G, Seagrave D (Eds.), Menta health screening and assessment in juvenile justice. Guilford Press, New York, USA, p. 44-70.

24. Andershed H, Hodgins S, Tengstrom A (2007) Convergent validity of the Youth Psychopathic Traits Inventory (YPI): Association with the Psychopathy Checklist: Youth Version (PCL:YV). Assessment 14(2): 144-154.

25. Sharp C, Kine S (2008) The assessment of juvenile psychopathy: Strengths and weaknesses of currently used questionnaire measures. Child and Adolescent Mental Health 13(2): 85-95.

26. Skeem JL, Cauffman E (2003) Views of the downward extension: Comparing the youth version of the Psychopathy Checklist with the Youth Psychopathic Traits Inventory. Behav Sci Law 21(6): 737-770.

27. Ansel LL, Barry CT, Gillen CTA, Herrington LL (2015) An analysis of four self-report measures of adolescent callous-unemotional traits: Exploring unique prediction of delinquency, aggression, and conduct problems. Journal of Psychopathology and Behavioral Assessment 37: 207-216.

28. Andershed H, Kerr M, Stattin H, Levander S (2002) Psychopathic traits in non-referred youths: A new assessment tool. In Blaauw E, \& Sheridan L (Eds.), Psychopaths: Current International Perspectives. The Hague: Elsevier, pp. 131-158.

29. Frick PJ, Hare RD (2001) The Antisocial Process Screening Device. Multi-Health Systems, Toronto, Canada.

30. Hare RD (1991) The Hare Psychopathy Checklist-Revised. MultiHealth Systems, Toronto, Ontario, Canada.

31. Frick PJ (2004) Inventory of callous-unemotional traits. Unpublished rating scale. University of New Orleans, New Orleans, LA.

32. Berkout OV, Young JN, Gross AM (2011) Mean girls and bad boys: Recent research on gender differences in conduct disorder. Aggression and Violent Behavior 16(6): 503-511.
33. Branson CE, Cornell DG (2008) Correspondence of the Millon Adolescent Clinical Inventory (MACI) and the Personality Inventory for Youth (PIY) in juvenile offenders. Journal of Forensic Psychology Practice 7(4): 65-100.

34. Murrie DC, Cornell DG (2002) Psychopathy screening of incarcerated juveniles: A comparison of measures. Psychol Assess 14(4): 390-396.

35. Penney SR, Skilling TA (2012) Moderators of informant agreement in the assessment of adolescent psychopathology: Extension to a forensic sample. Psychol Assess 24(2): 386-401.

36. Seals RW, Sharp C, Ha C, Michonski JD (2012) The relationship between the Youth Psychopathic Traits Inventory and psychopathology in a U.S. community sample of male youth. J Pers Assess 94(3): 232-243.

37. Smith SR (2007) Making sense of multiple informants in child and adolescent psychopathology: A guide for clinicians. Journal of Psychoeducational Assessment 25(2): 139-149.

38. Vermeiren R (2003) Psychopathology and delinquency in adolescents: A descriptive and developmental perspective. Clin Psychol Rev 23(2): 277-318.

39. Dévieux J, Malow R, Stein JA, Jennings TE, Lucenko BA (2002) Impulsivity and HIV risk among adjudicated alcohol- and other drugabusing adolescent offenders. AIDS Educ Prev 14(5 Suppl B): 24-35.

40. Lachar D, Hammer BA, Hammer JH (2006) The Personality Inventory for Youth, the Personality Inventory for Children, Second Edition, and the Student Behavior Survey. In: Archer RP (Ed.), Forensic uses of clinical assessment instruments. Lawrence Erlbaum Associates, Mahwah, New Jersey, USA, pp. 263-296.

41. Pinsoneault TB (1996) Rationally developed fake-good and fakebad scales for the Jesness Inventory. Journal of Psychopathology and Behavioral Assessment 18(3): 255-273.

42. Kahn RE, Frick PJ, Youngstrom EA, Kogos Youngstrom J, Feeny NC, et al. (2013) Distinguishing primary and secondary variants of callousunemotional traits among adolescents in a clinic-referred sample. Psychol Assess 25(3): 966-978.

43. Vincent GM, Kimonis ER, Clark A (2016) Juvenile psychopathy: Appropriate and inappropriate uses in legal proceedings. In: Heilbrun K, DeMatteo D, et al. (Eds.), APA Handbook of psychology and juvenile justice. American Psychological Association, Washington, DC, USA, pp. 197-232.

44. Boccaccini MT, Epstein M, Poythress N, Douglas KS, Campbell J (2007) Self-report measures of child and adolescent psychopathy as predictors of offending in four samples of justice-involved youth. Assessment 14(3): 361-374.

45. Colins OF, Bijttebier P, Broekaert E, Andershed H (2014) Psychopathiclike traits among detained female adolescents: Reliability and validity of the Antisocial Process Screening Device and the Youth Psychopathic Traits Inventory. Assessment 21(2): 195-209.

46. Dolan MC, Rennie CE (2007) The relationship between psychopathic traits measured by the Youth Psychopathic Trait Inventory and psychopathology in a UK sample of conduct disordered boys. J Adolesc 30(4): 601-611.

47. Kruh IP, Frick PJ, Clements CB (2005) Historical and personality correlates to the violence patterns of juveniles tried as adults. Criminal Justice and Behavior 32(1): 69-96.

48. Vahl P, Colins OF, Lodewijks HP, Markus MT, Doreleijers TA, et al. (2014) Psychopathic-like traits in detained adolescents: Clinical usefulness of self-report. Eur Child Adolesc Psychiatry 23(8): 691-699.

49. Fink BC, Tant AS, Tremba K, Kiehl KA (2012) Assessment of psychopathic traits in an incarcerated adolescent sample: A 
methodological comparison. J Abnorm Child Psychol 40(6): 971-986.

50. Frick PJ, Barry CT, Bodin SD (2000) Applying the concept of psychopathy to children: Implications for the assessment of antisocial youth. In C.B. Gacono (Ed.), The clinical and forensic assessment of psychopathy: A practitioner's guide Lawrence Erlbaum, USA, pp. 3-24

51. Heilbrun K (1992) The role of psychological testing in forensic assessment. Law and Human Behavior 16: 257-272.

52. Fleenor JW (2005) Review of the Hare Psychopathy Checklist: Youth Version. In: Spies RA \& Plake BS (Eds.), The sixteenth mental measurements yearbook. Lincoln, NE: Buros Institute of Menta Measurements. Retrieved from Mental Measurements Yearbook with Tests in Print database.

53. Ellen AS (2005) Review of the Antisocial Process Screening Device In: Spies RA \& Plake BS (Eds.), The sixteenth mental measurements yearbook. Lincoln, NE: Buros Institute of Mental Measurements. Retrieved from Mental Measurements Yearbook with Tests in Print database.

54. Viljoen JL, McLachlan K, Vincent GM (2010) Assessing violence risk and psychopathy in juvenile and adult offenders: A survey of clinical practices. Assessment 17(3): 377-395.

55. Singh JP, Grann M, Fazel S (2011) A comparative study of violence risk assessment tools: A systematic review and metaregression analysis of 68 studies involving 25,980 participants. Clin Psychol Rev 31(3): 499-513.

56. Catchpole REH, Gretton HM (2003) The predictive validity of risk assessment with violent young offenders: A 1-year examination of criminal outcome. Criminal Justice and Behavior 30(6) 688-708.

57. Caldwell MF, McCormick D, Wolfe J, Umstead D (2012) Treatmentrelated changes in psychopathy features and behavior in adolescent offenders. Criminal Justice and Behavior 39(2): 144-155.
58. Lawing K, Frick PJ, Cruise KR (2010) Differences in offending patterns between adolescent sex offenders high or low in callous-unemotional traits. Psychol Assess 22(2): 298-305.

59. Butcher JN, Williams CL, Graham JR, Archer RP, Tellegen A, et al. (1992) Minnesota Multiphasic Personality Inventory-Adolescent (MMPI-A): Manual for administration, scoring, and interpretation. University of Minnesota Press, Minneapolis, MN, USA

60. Millon T (1993) Millon Adolescent Clinical Inventory. Minneapolis, $\mathrm{MN}$ : National Computer Systems.

61. Caputo AA, Frick PJ, Brodsky SL (1999) Family violence and juvenile sex offending: The potential mediating role of psychopathic traits and negative attitudes toward women. Criminal Justice and Behavior 26(3): 338-356.

62. Pardini DA (2006) The callousness pathway to severe violent delinquency. Aggressive Behavior 32(6): 590-598.

63. Pechorro P, Jiménez L, Hidalgo V, Nunes C (2015) The DSM-5 limited prosocial emotions subtype of conduct disorder in incarcerated male and female juvenile delinquents. Int J Law Psychiatry 39: 77-82.

64. Crowne DP, Marlowe D (1964) The approval motive: Studies in evaluative dependence. John Wiley, New York, USA.

65. Edwards AL, Clark CL (1987) Social desirability and dispersions for the items in two SD scales: The MMPI SD scale and an experimental SD scale. Psychological Reports 60: 1083-1086.

66. Crandall VC, Crandall VJ, Katkovsky W (1965) A children's social desirability questionnaire. J Consult Psychol 29: 27-36.

67. De Los Reyes A, Augenstein TM, Wang M, Thomas SA, Drabick DA, et al. (2015) The validity of the multi-informant approach to assessing child and adolescent mental health. Psychol Bull 141(4): 858-900. 